\title{
PARP-1 Inhibitor Attenuates Cocaine-Induced Hepatotoxicity
}

\author{
J.D. McCluskey, S.C. Harbison, D. Sava, G.T. Johnson* and R.D. Harbison \\ Department of Environmental and Occupational Health, College of Public Health, University of South Florida, Tampa, \\ FL, USA
}

\begin{abstract}
Cocaine abuse is associated with multiple health problems including occasional hepatic failure and death. The mechanism of cocaine-induced hepatotoxicity $(\mathrm{CIH})$ is not clear, although studies in mice have demonstrated that cocaine-induced liver injury may be mediated by nitric oxide and reactive oxygen species. Recently, we have found that cocaine increases poly (ADP-ribose) polymerase (PARP) activity in the liver. Therefore, inhibition of PARP may block CIH. A preliminary assessment of the PARP inhibitor 3,4-Dihydro-5-[4-(1-piperidinyl)butoxyl]-1(2H)-isoquinolinone (DPQ) in ICR mice failed to attenuate CIH. However, the PARP inhibitor 1,5-dihydroxyisoquinoline (DIQ) successfully attenuated CIH. Mean ALT activity of 569 IU caused by cocaine treatment alone, was limited to 79 IU in ICR mice concomitantly treated with DIQ $(10 \mathrm{mg} / \mathrm{kg}$, ip). The protective effect of DIQ was also associated with prevention of development of lipid peroxidation in liver tissue, reduced depletion of glutathione (GSH), and a reduced production of nitrites. Cocaine-induced TBARS was significantly decreased by DIQ from a mean of $5.7 \mathrm{nmol} / \mathrm{mg}$ protein to a mean of $2.5 \mathrm{nmol} / \mathrm{mg}$ protein, similar to untreated mice. Hepatic GSH was reduced more than 2 fold following cocaine administration but treatment with DIQ conserved GSH at the level of untreated mice. The protective effect of DIQ in attenuating $\mathrm{CIH}$ can potentially be explained by the dual inhibitory effect of DIQ that reduces induction of PARP and inducible nitric oxide synthetase (iNOS). The DIQ attenuation of CIH provides evidence for a PARP and iNOS modulated mechanism of action for this hepatocellular pathology.
\end{abstract}

Keywords: PARP-1, Cocaine, Hepatotoxicity, PARP Inhibitors.

\section{INTRODUCTION}

Cocaine abuse is associated with multiple medical problems including occasional hepatic failure and consequent death. Cocaine-induced hepatotoxicity $(\mathrm{CIH})$ has been demonstrated in both humans and experimental animals [1-4]. However, the mechanism of CIH has not been clearly elucidated, although it has been demonstrated that transformation of cocaine to norcocaine by cytochrome P450 produces nitric oxide [5-7]. Free radicals produced in the liver during metabolic transformation of cocaine may cause mitochondrial impairment and nuclear DNA damage, leading to the activation of DNA repair mechanisms such as poly(ADP-ribose) polymerase 1 (PARP-1) induction [8]. Upon binding to damaged DNA, PARP-1 forms long branches of ADP-ribose polymers. Under normal cellular conditions, this activity provides protection of DNA; however the excessive activation of PARP-1 leads to rapid depletion of $\mathrm{NAD}^{+}$and ATP that eventually ends with cell death [9].

Previously, we have observed the ability of the PARP inhibitor $6(5 \mathrm{H})$-phenanthridinone to render hepatoprotective effects in animal models $[10,11]$. However, $6(5 \mathrm{H})$ phenanthridinone was required to be injected in dimethyl sulfoxide solution due to low water solubility, which potentially compromises bioavailability and possibly reduces

*Address correspondence to this author at the Department of Environmental and Occupational Health, College of Public Health, University of South Florida, Tampa, FL, USA; Tel: 813-974-3467; Fax: 813-905-9912;

E-mail: rharbiso@health.usf.edu the hepatoprotective effect. Recently, several novel watersoluble PARP-1 inhibitors have been developed and tested in various models of toxic exposure [12]. We have previously demonstrated the ability of several water-soluble PARP-1 inhibitors including 3-aminobenzamide (ABA), 5aminoisoquinolinone (AIQ), and $N$-(6-oxo-5,6-dihydrophenanthridin-2-yl)- $N, N$-dimethylacetamide $\mathrm{HCl}$ (PJ-34) to block or attenuate centrilobular hepatotoxicity in a carbon tetrachloride model of hepatotoxicity [13].

Cocaine has also been demonstrated to activate PARP-1 when producing hepatotoxicity $[14,15]$. There is therapeutic potential for poly(ADP-ribose) polymerase inhibitors to protect the liver against the side effects of cocaine [16-18]. The aim of this study was to determine the efficacy of two water soluble PARP inhibitors 3,4-Dihydro-5-[4-(1piperidinyl)butoxyl]-1(2H)-isoquinolinone (DPQ) and 1,5dihydroxyisoquinoline (DIQ) in attenuating cocaine induced hepatotoxicity, and to elucidate the possible mechanism(s) of their hepatoprotective effect in order to better understand the role of PARP-1 activation in cocaine induced hepatotoxicity.

\section{MATERIALS AND METHODS}

\section{Materials}

Cocaine was purchased from Fisher Scientific. Malondialdehyde bis (dimethyl acetal), thiobarbituric acid, and 5,5'-dithiobis-2-nitrobenzoic acid were obtained from Sigma Chemical Co. (St. Louis, MO). The Alanine Amino Transferase (ALT) kit was obtained from TECO Diagnostics (Anaheim, CA). The colorimetric assay for PARP activity was from Trevigen, Inc. (Gaithersburg, MD) All other 
chemicals were of analytical grade or higher from Merck (Darmstadt, Germany).

\section{Animals and Treatment}

Adult male ICR mice $(30 \pm 5 \mathrm{~g})$ were used for all experiments. Animals were housed under controlled conditions $\left(25 \pm 2{ }^{\circ} \mathrm{C}\right.$ and a $12 \mathrm{~h}$ light/dark cycle) and allowed free access to food and water. The animals were divided into the following groups: pure control group received no cocaine or PARP inhibitor, the positive control group received cocaine alone, and experimental group received cocaine and PARP inhibitor. Cocaine was dissolved in normal saline and administered intraperitoneally (ip) with a dose of $60 \mathrm{mg} / \mathrm{kg}$. PARP inhibitors were dissolved in normal saline and administered intraperitoneally in the following time intervals after cocaine injection: 0,1 and 2 hours. Each time interval represents an independent treatment group and each animal received a single dose. The injection sites for cocaine and PARP inhibitors were administered distant to one another to avoid chemical interaction. All the experiments were conducted under controlled conditions according to the Guide for the Care and Use of Experimental Animals and the University of South Florida Institutional Animal Care and Use Committee (IACUC). The mice were sacrificed after $24 \mathrm{~h}$ and blood samples to determine alanine transaminase (ALT) activity and nitrite content were withdrawn by cardiac puncture. Livers were isolated, perfused with normal saline, and dissected for histopathology and stored at $-80^{\circ} \mathrm{C}$ for determination of total GSH, thiobarbituric acid-reactive substances (MDA), PARP activity.

\section{Determination of PARP Activity}

The colorimetric assay for PARP activity was performed in 96-well plates (Trevigen, Inc., Gaithersburg, MD) according to manufacturer's protocol. Serial dilutions of the PARP enzyme were distributed into wells to generate a standard curve. To determine cellular PARP activity, 10 $\mu \mathrm{L} /$ well of the tissue homogenates, prepared according to manufacturer recommendations, were distributed in triplicates. The reactions were allowed to proceed for $1 \mathrm{~h}$ at room temperature. The plate was washed 4 times with $1 \times$ phosphate-buffered saline (PBS) and then incubated for 20 min with $50 \mu \mathrm{L} /$ well Streptavidin-horseradish peroxidase (Strep-HRP) diluted 1:500 in 1× Strep-Diluent (Trevigen). The plate was washed 4 times with $1 \times$ PBS prior to the addition of the HRP substrate. For colorimetric readout, 50 $\mu \mathrm{L}$ of TACS-Sapphire (Trevigen) was added to each well and incubated in the dark, at room temperature, for $15 \mathrm{~min}$. Development of the colorimetric reaction was stopped by the addition of an equal volume of $0.2 \mathrm{M} \mathrm{HCl}$. This generated a yellow color that was read at $450 \mathrm{~nm}$. The results were expressed as units of PARP activity calculated per milligram of protein and normalized to equal concentrations of protein. Protein determination in all assays described here were carried out with the bicinchoninic acid assay using bovine serum albumin as standard [19].

\section{Alanine Transaminase Activity}

ALT activity, expressed as IU/L, was determined by a previously described method using a commercially prepared reagent kit from TECO Diagnostics (Anaheim, CA) [20]. Serum $(0.2 \mathrm{~mL})$ was obtained by centrifugation of cardiac puncture blood samples at $4000 \mathrm{rpm}$ for $15 \mathrm{~min}$. Each serum sample was then transferred to a new sterile microcentrifuge tube and stored at $4{ }^{\circ} \mathrm{C}$ until time of assay. ALT activity was expressed as IU/L.

\section{Glutathione Assay}

Total GSH was determined as described previously by [21], Individual liver samples $(100 \mathrm{mg})$ were homogenized in $1 \mathrm{~mL}$ of $0.2 \mathrm{M} \mathrm{PBS}(\mathrm{pH} 8.0)$ and the mixture was centrifuged at $12,000 \mathrm{rpm}$ for $30 \mathrm{~min}$. The supernatant $(0.5$ $\mathrm{mL}$ ) was mixed with $0.5 \mathrm{~mL}$ of $4 \%$ sulfosalicylic acid, allowed to stand for $5 \mathrm{~min}$ at $4{ }^{\circ} \mathrm{C}$, and centrifuged again at $3000 \mathrm{rpm}$ for $10 \mathrm{~min}$. The supernatant obtained $(0.5 \mathrm{~mL})$ was mixed with $2 \mathrm{~mL}$ of $0.2 \mathrm{M}$ PBS $(\mathrm{pH} 8.0)$ and $10 \mu \mathrm{L}$ of $10 \mathrm{mM}$ 5,5'-dithiobis-2-nitrobenzoic acid [22]. The absorbance was measured at $412 \mathrm{~nm}$ and concentration of GSH was expressed as nmol/mg protein.

\section{Lipid Peroxidation Assay}

Formation of lipid peroxide derivatives was evaluated by measuring TBARS according to a method previously described by [23]. Liver samples were homogenized in icecold $1.15 \% \mathrm{KCl}(\mathrm{w} / \mathrm{v})$. Homogenates $(0.4 \mathrm{~mL})$ were mixed with $1 \mathrm{~mL}$ of $0.375 \%$ TBA, $15 \%$ trichloroacetic acid (TCA) $(\mathrm{w} / \mathrm{v}), 0.25 \mathrm{~N} \mathrm{HCl}$, and $6.8 \mathrm{mM}$ butylated-hydroxytoluene, placed in a boiling water bath for $10 \mathrm{~min}$, removed and allowed to cool on ice. Following centrifugation at $3000 \mathrm{rpm}$ for $10 \mathrm{~min}$, the absorbance in the supernatants was measured at $532 \mathrm{~nm}$. The amount of TBARS produced was expressed as nmol TBARS/mg protein using malondialdehyde bis(dimethylacetal) (MDA) for calibration.

\section{Determination of Nitric Oxide (NO) Synthesis}

The production of NO was assessed indirectly by measuring the nitrite levels in the plasma using Griess reaction [24]. Plasma samples were diluted four times with distilled water and deproteinized by adding zinc sulfate to a final concentration of $1.5 \%$. After centrifugation at $10,000 \mathrm{~g}$ for $5 \mathrm{~min}$ at room temperature, $100 \mu \mathrm{L}$ supernatant was applied to a microliter plate well, followed by $100 \mu \mathrm{L}$ of Griess reagent consisting of $1 \%$ sulfanilamide and $0.1 \% \mathrm{~N}$ 1-naphthylethylenediaminedihydrochloride in 5\% phosphoric acid). The absorbance was read after $10 \mathrm{~min}$ of color development at room temperature with a micro reader at $540 \mathrm{~nm}$. Sodium nitrite was used to produce a calibration curve for calculation of total nitrite levels [25].

\section{Statistical Analysis}

Summary descriptive analysis for all cytotoxicity outcome data is reported as the mean levels of biomarkers and the standard error of the mean (SEM). One way ANOVA was performed to evaluate the differences between all treatment groups and the cocaine control group, as well as the negative control group ( $\mathrm{p}<0.05$ was considered to indicate a statistically significant difference).

\section{RESULTS}

PARP activity (Fig. 1) assessed in the livers of ICR mice intoxicated with cocaine $(60 \mathrm{mg} / \mathrm{kg}$, ip) $(\mathrm{n}=7)$ was elevated 1.5 times as compared to untreated animals' level of $4.6 \pm 0.8$ $\mathrm{U} / \mathrm{mg}$ protein $(\mathrm{n}=6)$ with borderline statistical significance $(\mathrm{p}=0.0979)$. Both DPQ $(\mathrm{n}=5)$ and DIQ $(\mathrm{n}=5)$ injected 


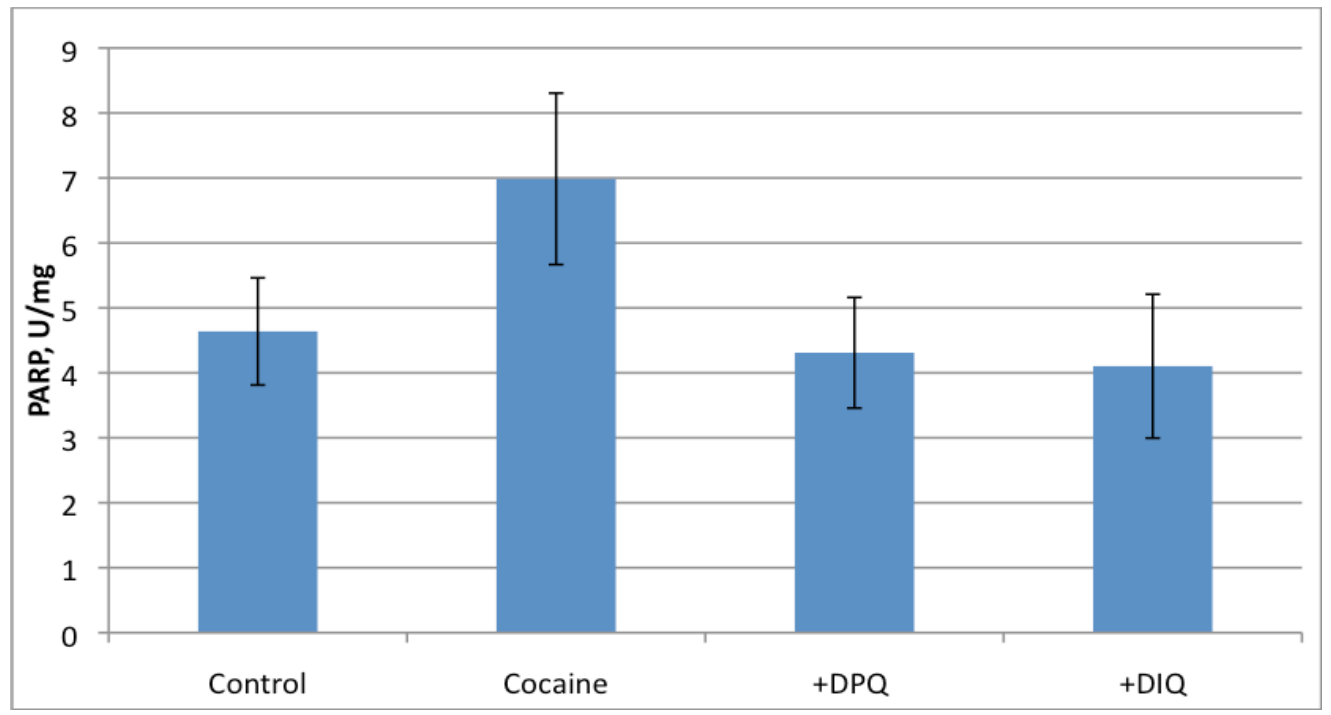

Fig. (1). PARP-1 activity in the liver of ICR mice untreated (Control) treated with cocaine (Cocaine) and treated concomitantly with cocaine and DPQ (+DPQ) or cocaine and DIQ (+DIQ). Measurements are mean PARP U/mg, \pm SEM.

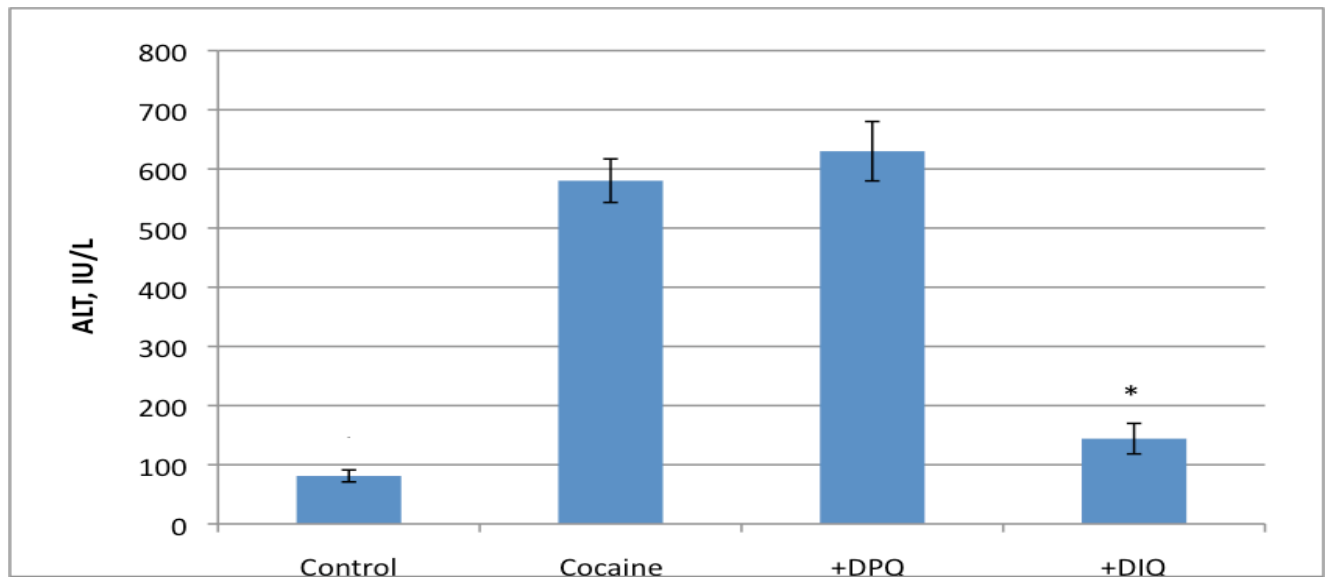

Fig. (2). Alanine transaminase (ALT) in ICR mice untreated (Control) treated with cocaine (Cocaine) and treated concomitantly with cocaine and DPQ (+DPQ) or cocaine and DIQ (+DIQ). Measurements are mean ALT IU/L, \pm SEM. An '*' indicates $\mathrm{p}<0.05$ compared to cocaine treatment alone.

concomitantly with cocaine lowered the mean elevation of PARP-1 activity in livers of observed mice approaching statistical significance compared to cocaine only treated mice ( $\mathrm{p}=0.0744$ and $\mathrm{p}=0.0560$ respectively). At equal doses of $10 \mathrm{mg} / \mathrm{kg}$, concomitant treatment of DPQ and DIQ with cocaine returned the activity of PARP-1 in the liver of ICR mice to the level of untreated controls $(p=0.8264$ and $p=$ 0.7214 respectively compared to untreated mice). Thus, the tested inhibitors demonstrated ability to hinder the elevation of PARP activity elicited by cocaine.

Intraperitoneal administration of $60 \mathrm{mg} / \mathrm{kg}$ cocaine $(\mathrm{n}=6)$ elicited substantial elevation of serum ALT activity in ICR mice 24 hours post injection (Fig. 2). There was no statistically significant difference in serum ALT activity resulting from concomitant administration of cocaine and DPQ $(10 \mathrm{mg} / \mathrm{kg})(\mathrm{n}=6)$ as compared to administration of cocaine alone. Concomitant treatment with $10 \mathrm{mg} / \mathrm{kg}$ of DIQ $(n=6)$ and cocaine resulted in significant reduction in ALT, producing mean ALT levels $75 \%$ less than mice treated with cocaine alone.

As DIQ demonstrated preliminary efficacy in attenuating $\mathrm{CIH}$ from cocaine insult, this PARP inhibitor was selected for dose response evaluation. Dose dependence for DIQ when administered concomitantly with cocaine demonstrated that the effect on ALT attenuation from cocaine insult plateaued at doses exceeding $10 \mathrm{mg} / \mathrm{kg}$, without further substantial reduction at $20 \mathrm{mg} / \mathrm{kg}$ (Fig. 3). For all groups in this experiment $(\mathrm{n}=6)$.

The time dependence of administration of DIQ was evaluated through administration of DIQ $10 \mathrm{mg} / \mathrm{kg}$ at 0,1 , and 2 hours post cocaine treatment (Fig 4). Concomitant administration of cocaine and DIQ $(n=6)$ resulted in a statistically significant reduction of ALT compared to cocaine alone. Administration of DIQ $1(n=6)$ and 2 hours $(n=5)$ after cocaine treatment modestly reduced mean serum ALT levels, but this effect was not statistically significant.

Total glutathione (reduced and oxidized) was measured in liver samples 24 hours after intoxication. Administration of cocaine alone $(n=6)$ resulted in 2.2-fold reduction in GSH, while concomitant administration of DIQ $(n=6)$ conserved GSH near the control level (Fig. 5). Delayed injection of DIQ decreased efficacy of DIQ with decreased GSH levels observed in mice treated with DIQ 1 hour after cocaine treatment $(n=6)$ compared to concomitantly treated mice, 


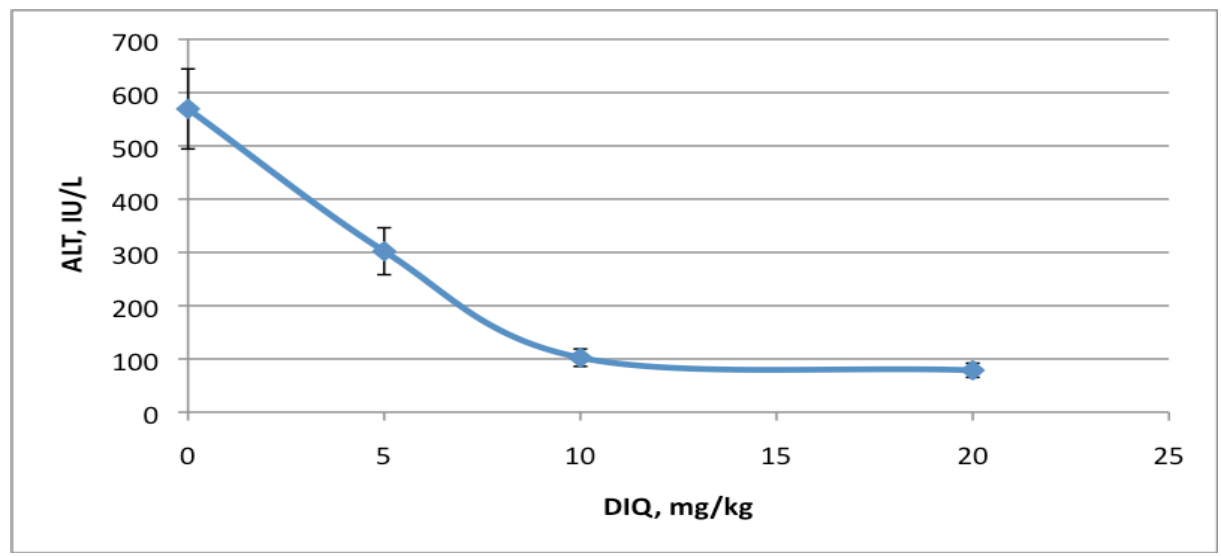

Fig. (3). Dose Dependence of DIQ on Alanine Transaminase

Reduction of elevation of ALT caused by concomitant administration of $0,5,10$, and $20 \mathrm{mg} / \mathrm{kg}$ DIQ and $60 \mathrm{mg} / \mathrm{kg}$ of cocaine. Measurements are reported as the mean ALT IU/L \pm SEM.

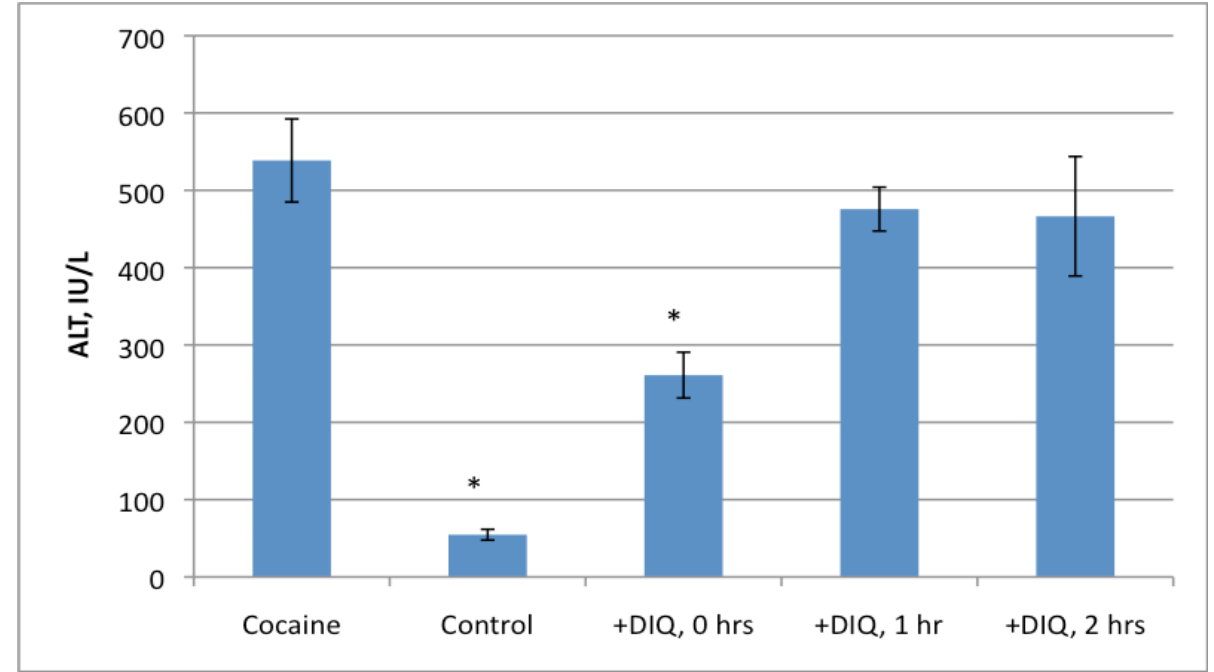

Fig. (4). Time Dependence of DIQ on Alanine Transaminase

Alanine transaminase levels in ICR mice treated with DIQ $10 \mathrm{mg} / \mathrm{kg}$ at 0,1 , and 2 hours after treatment with cocaine $60 \mathrm{mg} / \mathrm{kg}$. Measurements are reported as the mean ALT IU/L $\pm \mathrm{SEM}$. An '*' indicates $\mathrm{p}<0.05$ compared to cocaine treatment alone.

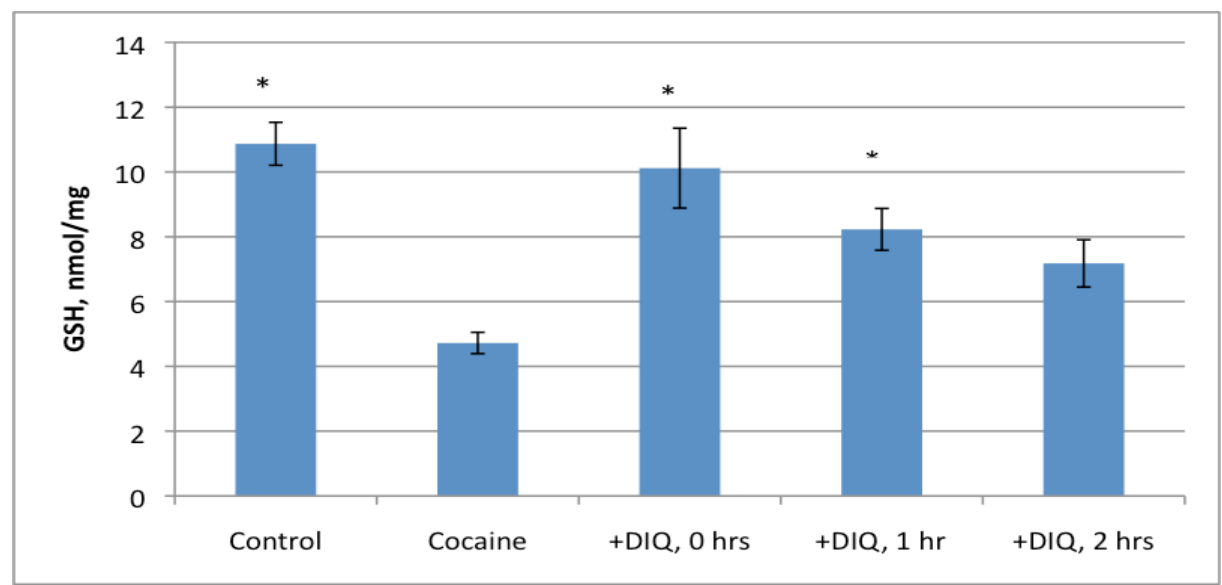

Fig. (5). Total liver glutathione concentration in ICR mice treated with DIQ $10 \mathrm{mg} / \mathrm{kg}$ at 0,1 , and 2 hours after treatment with cocaine 60 $\mathrm{mg} / \mathrm{kg}$. Measurements are reported as the mean GSH nmol $/ \mathrm{mg} \pm \mathrm{SEM}$. An '*' indicates $\mathrm{p}<0.05$ compared to cocaine treatment alone.

though this group produced significantly higher GSH levels than the cocaine only treated mice. Mice treated with DIQ 2 hours after treatment with cocaine $(n=5)$ produced GSH levels 1.5 times higher as compared to the level of cocaine alone, though this effect was not statistically significant.
Changes in MDA, which reflects involvement of free radical oxidation in development of hepatotoxicity, were evaluated in ICR mice livers (Fig. 6). In mice treated with cocaine only $(n=7)$, the level of MDA was elevated 2.5 times as compared to untreated controls $(n=6)$ at 2.5 


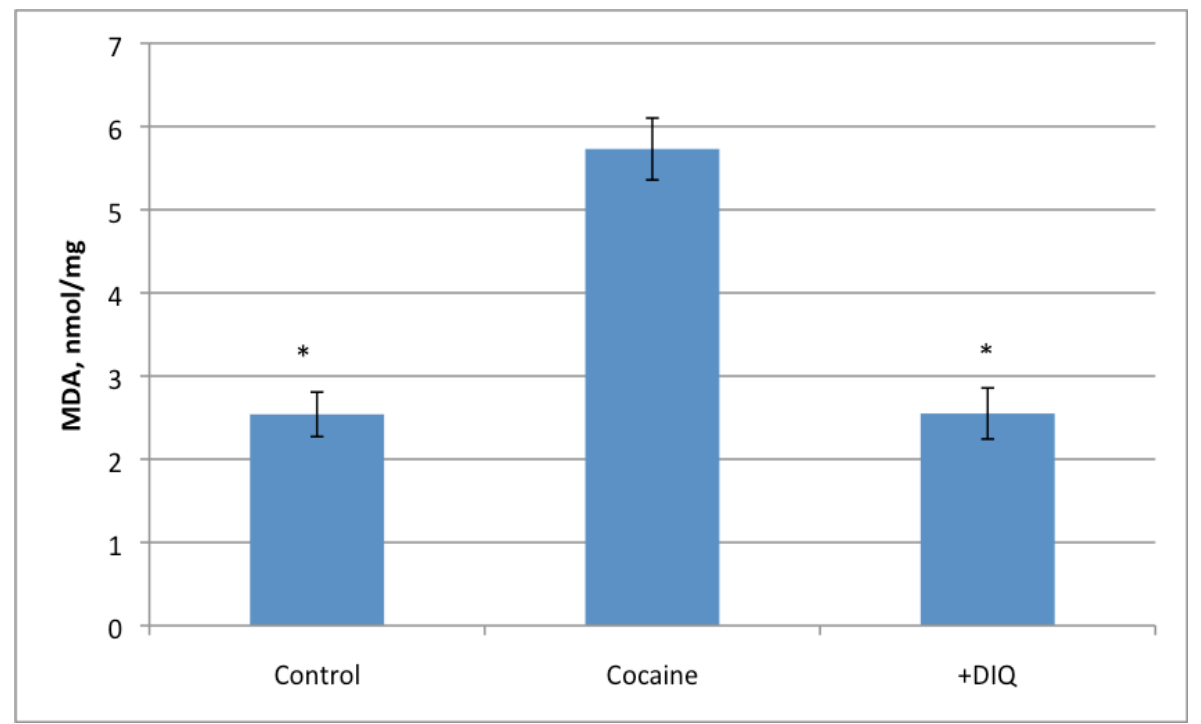

Fig. (6). Hepatic lipid peroxidation in ICR mice untreated (Control), treated with cocaine (Cocaine) and treated concomitantly with cocaine and DIQ (+DIQ). Measurements are mean MDA nmol/mg, \pm SEM. An '*' indicates $\mathrm{p}<0.05$ compared to cocaine treatment alone.

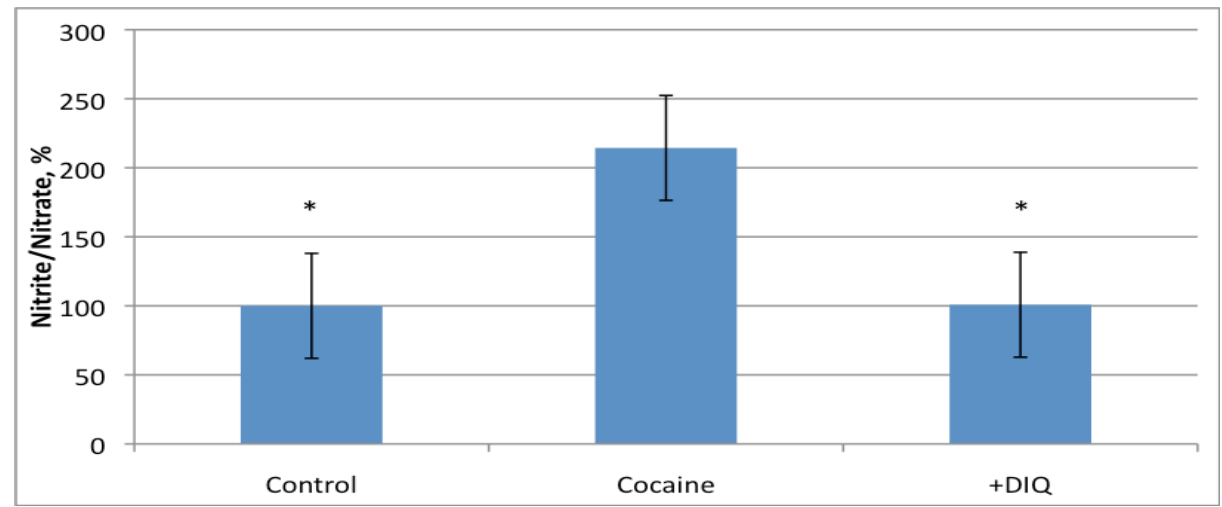

Fig. (7). Nitrite Index

Nitrite in the plasma of ICR mice untreated (Control) treated with cocaine (Cocaine) and treated concomitantly with cocaine and DIQ (+DIQ). Measurements are mean percentage of nitrate to nitrates, \pm SEM. An '*' indicates $\mathrm{p}<0.05$ compared to cocaine treatment alone.

$\mathrm{nmol} / \mathrm{mg}$ of protein. Cocaine-induced MDA values were significantly decreased by concomitant administration of DIQ with cocaine injection. DIQ treatment $(n=5)$ effectively reduced free radical activity to a similar level of the untreated control group, with no statistically significant difference between the mean MDA values of these two groups $(\mathrm{p}=1.0000)$.

\section{LIPID PEROXIDATION}

DIQ also demonstrated the inhibition of the production of nitrogen oxides shown by the reduction of nitrite (Fig. 7). Cocaine treatment alone $(n=6)$ produced mean nitrite levels 2.1 times higher compared than controls $(n=3)$. Administration of DIQ concomitantly with cocaine $(n=6)$ attenuated the nitrite index to the level of control (i.e. differences between untreated mice and mice treated concomitantly with DIQ and cocaine were not statistically significant $(\mathrm{p}=1.0000)$. Nitric oxide production appears to be an important factor in the pathology of CIH.

In addition to the evaluation of $\mathrm{CIH}$ with biomarker analysis, a seven-day mortality study was conducted for mice treated with $60 \mathrm{mg} / \mathrm{kg}$ cocaine alone and mice treated concomitantly with DIQ $10 \mathrm{mg} / \mathrm{kg}$ and cocaine $60 \mathrm{mg} / \mathrm{kg}$. It was found that mice concomitantly treated with DIQ and cocaine experienced zero mortality, while $61 \%$ of mice administered only cocaine died within the 7 day period.

Macroscopic examination of liver samples was in accordance with the biochemical findings. Gross anatomical findings showed hemorrhagic and necrotic damage in mice treated with cocaine. When DIQ was administered subsequent to cocaine, no pathological changes were observed.

\section{DISCUSSION}

PARP-1 inhibitors have been shown to be of therapeutic value in a number of pathological conditions including liver diseases. Several classes of competitive PARP-1 inhibitors have been reported including benzamide [26], 3,4-dihydro-5hydroxy-1(2H)-isoquinolinone (DIQ) [27], 3,4-dihydro-5[4-1(1-piperidinyl)buthoxy]-1(2H)-isoquinolinone (DPQ) [27], and 6(5H)-phenantridinone (PND) [26]. Among these, dihydroisoquinolinone derivatives, such as DPQ, have been of particular interest due to their high potency as PARP-1 inhibitors, with an IC50 of $2.2 \mu \mathrm{M}$ estimated in vitro [26, 28]. DIQ has been identified as a moderately potent PARP-1 inhibitor, with an IC50 of $17 \mu \mathrm{M}$ in vitro as observed by [27]. 
In this study we tested the ability of DPQ and DIQ to attenuate $\mathrm{CIH}$ and various biomarkers of toxicity that potentially modulate this process. Using serum ALT as a measure of damage to hepatic tissue we have demonstrated that administration of DIQ concomitantly and within 1 hour of cocaine treatment renders a protective effect against the hepatotoxicity of cocaine. DIQ was able to reduce serum ALT levels up to $75 \%$ as compared to cocaine treatment alone. These results were confirmed with a 7 day mortality study in which concomitant treatment with cocaine and DIQ prevented mortality from occurring in treated mice and prevented gross pathological changes associated with cocaine induced hepatotoxicity. While the specific mechanisms for this effect are not clear, evidence suggests $\mathrm{CIH}$ is partially modulated by PARP-1 activation in the cascade of reactive oxygen species produced by cocaine exposure.

Development of hepatotoxicity elicited by cocaine is also associated with reduction of GSH levels. Depletion of GSH causes liver cells to become more susceptible to lipid peroxidation and studies have shown that inhibition of oxidative metabolism attenuates cocaine mediated hepatotoxicity $[29,30]$. Therefore, preservation of GSH should also play a role in modulating $\mathrm{CIH}$.

The current study indicates that GSH levels are preserved to levels similar to that of untreated mice in the animals treated with DIQ concomitantly with cocaine. The prevention of the deleterious effects of reactive species with treatment of DIQ was also demonstrated by measurements of lipid peroxidation represented by MDA. Cocaine treated mice demonstrated elevation of MDA in the liver on average twice that of untreated controls. Animals treated simultaneously with cocaine and DIQ did not produce hepatotoxicity and demonstrated significantly reduced MDA levels in addition to reduced ALT, preserved GSH, and the absence of abnormal histopathology.

Overproduction of NO in the liver has been implicated as an important event in different models of hepatic inflammation and injury [31,32]. NO is known to react with superoxide radical, forming peroxynitrite, which has been identified as a more powerful oxidizing agent. This may cause GSH depletion, free radical generation, and up-regulation of iNOS [33]. In the current study we demonstrated that under acute cocaine intoxication significant elevations of nitrite levels are observed in blood plasma.

This study has shown that DIQ, a specific PARP-1 inhibitor, also attenuates nitrite elevation and can effectively block cocaine induced hepatotoxicity. This observation in combination with the results of DPQ treatment, which did not effectively block $\mathrm{CIH}$, indicate that modulation of this process requires not only PARP-1 inhibition, but also a combination of modulating properties potentially related to iNOS associated metabolic processes [34]. The results of this study could have important implications for pharmaceutical interventions in the treatment of cocaine users, particularly for issues of hepatotoxicity [35].

\section{CONCLUSION}

This study demonstrated that the PARP-1 inhibitor DIQ has the capacity to attenuate the toxic effects of cocaine in the liver. A potential mechanism for this protective effect is thought to be due to its ability to control PARP activity within the physiological norm. The protective effect of DIQ is also linked with the ability to prevent lipid peroxidation in liver tissue and improve the antioxidant defenses as demonstrated by the amelioration of elevated MDA and maintenance of glutathione levels. However, the most important factor could be associated with involvement of the iNOS metabolic pathway in the development of $\mathrm{CIH}$. Treatment with DIQ had an inhibitory effect on plasma nitrite levels, which suggests the involvement of inducible nitric oxide synthetase (iNOS) in cocaine toxicity. The mechanism of action for DIQ in the attenuation of CIH can be potentially explained by a dual inhibitory effect that limits PARP-1 induction and iNOS activity. Further detailed studies elucidating the biochemical mechanisms responsible for the hepatoprotective effect of DIQ are needed.

\section{CONFLICT OF INTEREST}

The authors confirm that this article content has no conflicts of interest.

\section{ACKNOWLEDGEMENT}

Declared none.

\section{REFERENCES}

[1] Kanel GC, Cassidy W, Shuster L, Reynolds TB. Cocaine-induced liver cell injury: comparison of morphological features in man and in experimental models. Hepatology 1990; 11: 646-51.

[2] Wanless IR, Dore S, Gopinath N, et al. Histopathology of cocaine hepatotoxicity. Gastroenterology 1990; 98: 497-501.

[3] Labib R, Turkall R, Abdel-Rahman MS. Oral cocaine produces dose-related hepatotoxicity in male mice. Toxicol Lett 2001; 125: 29-37.

[4] Labiba R, Turkalla R, Abdel-Rahmana MS. Inhibition of cocaine oxidative metabolism attenuates endotoxin potentiation of cocaine mediated hepatotoxicity. Toxicology 2002; 179: 9-19.

[5] Aoki K, Ohmori M, Takimoto M, Ota H, Yoshida T. Cocaineinduced liver injury in mice is mediated by nitric oxide and reactive oxygen species. Eur J Pharmacol 1997; 336: 43-49.

[6] Díez-Fernández C, Zaragoza A, Alvarez AM, Cascales M. Cocaine cytotoxicity in hepatocyte cultures from phenobarbital-induced rats: involvement of reactive oxygen species and expression of antioxidant defense systems. Biochem Pharmacol 1999; 58: 797805.

[7] Reid MJ, Bornheim LM. The effects of phencyclidine pretreatment on cocaine-mediated hepatotoxicity in mice. Toxicol Appl Pharmacol 2001; 172: 194-202.

[8] Campo GM, Avenoso A, Campo S, et al. Hyaluronic acid and chondroitin-4-sulphate treatment reduces damage in carbon tetrachloride-induced acute liver injury. Life Sci 2004; 74: 1289305.

[9] Ha HC, Snyder SH. Poly(ADP-ribose) polymerase is a mediator of necrotic cell death by ATP depletion. Proc Natl Acad Sci USA1999; 96: 13978-82.

[10] Banasik M, Stedeford T, Ueda K, et al. Hepatoprotective effects of $6(5 \mathrm{H})$-phenanthridinone from chemical-induced centrilobular necrosis. Res Commun Mol Pathol Pharmacol 2004; 115: 15-20.

[11] Grivas PC, Tanaka S, Ueda K, Johnson G, Harbison RD. 6, (5H)phenanthridinone protects against carbon tetrachloride-induced cytotoxicity in human HepG2 cells. Res Commun Mol Pathol Pharmacol 2007; 120: 123-32.

[12] Thiemermann C. Development of novel, water-soluble inhibitors of poly(adenosine 5'-diphosphate ribose) synthetase activity for use in shock and ischemia-reperfusion injury. Crit Care Med 2002; 30: 1163-5.

[13] McCluskey JD, Sava D, Harbison SC, et al. Hepatoprotective effects of select water-soluble PARP inhibitors in a carbon tetrachloride model. Int J Crit Illn Inj Sci 2011; 1: 97-103. 
[14] Price DJ, Muro-Cacho CA, Harbison RD. The role of apoptosis in phenobarbital modulation of cocaine-induced liver damage. Res Commun Alcohol Subst Abuse 1999; 20: 27-40.

[15] Wang J-F, Ren X, DeAngelis J, et al. Differential patterns of cocaine-induced organ toxicity in murine heart versus liver. Exp Biol Med 2001; 226: 52-60.

[16] Virág L, Szabó C. The therapeutic potential of poly(ADP-ribose) polymerase inhibitors. Pharmacol Rev 2002; 54: 375-429.

[17] Virág L. Structure and function of poly(ADP-ribose) polymerase-1: role in oxidative stress-related pathologies. Curr Vasc Pharmacol 2005; 3: 209-14.

[18] Schreiber V, Dantzer F, Ame J-C, de Murcia G. Poly(ADP-ribose): novel functions for an old molecule. Nat Rev Mol Cell Biol 2006; 7: 517-28.

[19] Smith PK, Krohn RI, Hermanson GT, et al. Measurement of protein using bicinchoninic acid. Anal Biochem 1985; 150: 76-85.

[20] Reitman S, Frankel S. A colorimetric method for the determination of serum glutamic oxalacetic and glutamic pyruvic transaminases. Am J Clin Pathol 1957; 28: 56-63.

[21] Sedlak J, Lindsay RH. Estimation of total, protein-bound, and nonprotein sulfhydryl groups in tissue with Ellman's reagent. Anal Biochem 1968; 25: 192-205.

[22] Griffith OW. Determination of glutathione and glutathione disulfide using glutathione reductase and 2-vinylpyridine. Anal Biochem 1980; 106: 207-12.

[23] Cascio C, Guarneri R, Russo D, et al. Pregnenolone sulfate, a naturally occurring excitotoxin involved in delayed retinal cell death. J Neurochem 2000; 74: 2380-91.

[24] Green LC, Wagner DA, Glogowski J, Skipper PL, Wishnok JS, Tannenbaum SR. Analysis of nitrate, nitrite, and $[15 \mathrm{~N}]$ nitrate in biological fluids. Anal Biochem 1982; 126: 131-8.

[25] Bryan NS, Grisham MB. Methods to detect nitric oxide and its metabolites in biological samples. Free Radic Biol Med 2007; 43: 645-57.
[26] Banasik M, Komura H, Shimoyama M, Ueda K. Specific inhibitors of poly(ADP-ribose) synthetase and mono(ADP-ribosyl) transferase. J Biol Chem 1992; 267: 1569-75.

[27] Arundel-Suto CM, Scavone SV, Turner WR, Suto MJ, SeboltLeopold JS. Effect of PD 128763, a new potent inhibitor of poly(ADP-ribose) polymerase, on X-ray-induced cellular recovery processes in Chinese hamster V79 cells. Radiat Res 1991; 126: $367-71$.

[28] Moroni F, Meli E, Peruginelli F, et al. Poly(ADP-ribose) polymerase inhibitors attenuate necrotic but not apoptotic neuronal death in experimental models of cerebral ischemia. Cell Death Differ 2001; 8: 921-32.

[29] von Montfort C, Matias N, Fernandez A, et al. Mitochondrial GSH determines the toxic or therapeutic potential of superoxide scavenging in steatohepatitis. J Hepatol 2012 ([Epub ahead of print], doi:10.1016/j.jhep.2012.05.024).

[30] Labib R, Turkall R, Abdel-Rahman MS. Endotoxin potentiates the hepatotoxicity of cocaine in male mice. J Toxicol Environ Health A 2002; 65: 977-93.

[31] Olszanecki R, Gębska A, Jawień J, Jakubowski A, Korbut R. Inhibition of NOS-2 induction in LPS-stimulated J774.2 Cells by 1 , 5-isoquinolinediol, an inhibitor of PARP. J Physiol Pharmacol 2006; 57: 109-17.

[32] Jagtap P, Szabó C. Poly(ADP-ribose) polymerase and the therapeutic effects of its inhibitors. Nat Rev Drug Discov 2005; 4 : $421-40$.

[33] Foresti R, Clark JE, Green CJ, Motterlini R. Thiol compounds interact with nitric oxide in regulating heme oxygenase-1 induction in endothelial cells: involvement of superoxide and peroxynitrite anions. J Biol Chem 1997; 272: 18411-7.

[34] Elliott JC, Ijames SG, Lysle DT. Cocaine increases inducible nitric oxide synthase expression in rats: effects of acute and binge administration. Int Immunopharmacol 2003; 3: 1011-8.

[35] Ndikum-Moffor FM, Schoeb TR, Roberts SM. Liver toxicity from norcocaine nitroxide, an N-oxidative metabolite of cocaine. $\mathrm{J}$ Pharmacol Exp Ther 1998; 284: 413-9. 